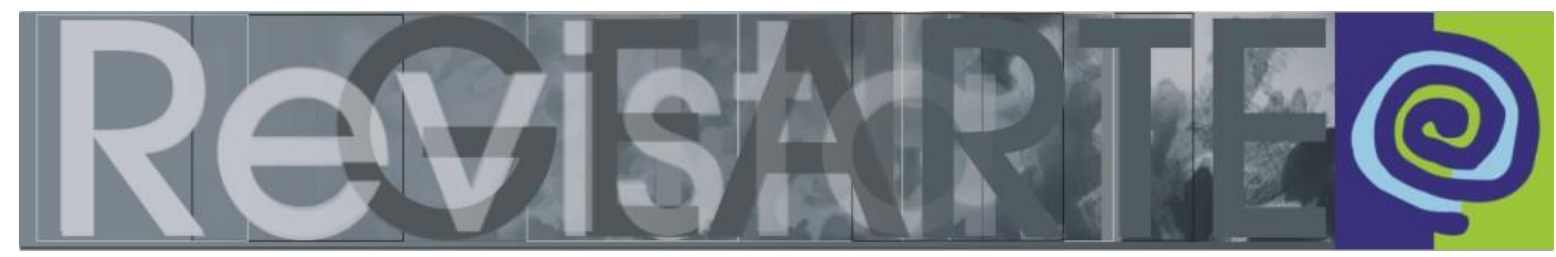

Volume 1, Número 2, Agosto/2014, ISSN 2357-9854

\title{
Museu Efêmero: $O$ Museu é o Mundo. Narrativas artísticas contemporâneas e patrimônio. Mobilização de relações entre pessoas, cidades e bens culturais.
}

\author{
Lilian do Amaral Nunes (UFG - Brasil)
}

\section{RESUMO}

O artigo aborda uma investigação que opera a partir de relações entre pessoas, cidades e patrimônio; articula os conceitos de Cartografias Culturais - sensibilidade e tecnicidade - e complementa-se com noções de Cartografia Social. Propõe pensar o mundo como um "museu" articulador do passado e do futuro, isto é, de memória e experimentação por meio da criatividade social, ação coletiva e práticas artísticas; um museu "explorador" do que no passado há de vozes excluídas, de alteridade e "resíduos", de memórias esquecidas. Ao estabelecermos uma aproximação entre museu e cidade, a cartografia social e cultural pode se converter em lugar onde se encontrem e dialoguem as múltiplas narrativas e as diversas temporalidades do mundo. Museu Efêmero pretende investigar as memórias e conectar cidades em rede por meio da experimentação e de dispositivos desenvolvidos nas práticas contemporãneas em artes e culturas visuais em contextos locais e iberoamericanos.

\section{PALAVRAS-CHAVE}

museu efêmero; cartografia social; práticas artísticas; experimentação; ação coletiva.

\begin{abstract}
This article discusses a research that operates with the concepts of cultural cartographies - sensitivity and technicity, complemented with notions of social cartography. We propose to think the world as an articulator "museum" of past and future, that is, memory experimentation through social creativity, collective action and artistic practices, in an "explorer" museum than in the past there excluded voices of otherness and "waste" of forgotten memories. Making an approximation between the museum and the city, the social and cultural cartography aim to be converted in places where multiple narratives can dialog with various temporalities of the world. Ephemeral Museum intends to investigate the memories, to connect cities and develop experiences in iberoamerican contexts.
\end{abstract}

KEYWORDS

ephemeral museum; social cartography; experimentation; art practices; collective action.

\section{Introdução}

$\mathrm{Na}$ contramão da tendência conservadora e da tentação apocalíptica do fatalismo, mas sem desconhecer tudo o que há de diagnóstico em ambas as atitudes, configura-se, atualmente, um modelo de política cultural que busca fazer do museu um lugar, não de apaziguamento, mas de tensionamento, mobilização, de choque, como diria Walter Benjamim, acerca da memória.

A possibilidade de que o museu chegue a converter-se nesse lugar vai requerer que perpasse por uma nova experiência de temporalidade que se concretiza no "sentimento de efêmero, provisório" que experimentamos na atualidade. Pois nessa sensação de provisoriedade há tanto a valorização do instantâneo, curto, superficial, 
frívolo, como de genuína experiência de desvanecimento, fugacidade, de fragmentação do mundo.

Podemos pensar o mundo como um "museu" articulador de passado e futuro, isto é, de memória com experimentação, de resistência contra a pretendida superioridade de umas culturas sobre as outras com diálogo e negociação cultural, por meio da criatividade social, ação coletiva e práticas artísticas. De um museu perscrutador do que no passado há de vozes excluídas, de alteridades e "resíduos", de memórias esquecidas, de restos e "desfeitos" da história cuja potencialidade de nos descentrarmos nos vacina contra a pretensão de fazer do museu uma "totalidade expressiva" da história ou da identidade nacional. Os desafios desta experiência pós moderna e culturalmente periférica resultam em que o museu seja transformado no espaço onde se encontrem e dialoguem as múltiplas narrativas do nacional, as memórias heterogêneas do latino-americano e das diversas temporalidades do mundo.

\section{O Museu é o mundo: criatividade social, ação coletiva, práticas artísticas}

Operamos com base em projetos que se configuram como dispositivos complexos baseados na análise de problemáticas detectadas em áreas específicas dos tecidos urbanos de cidades ibero-americanas como São Paulo e Barcelona, sobre as quais nos deteremos adiante. Instaura-se um debate de ideias a partir da articulação de grupos interdisciplinares de trabalho e a decorrente realização de propostas e projetos com base na concepção de cartografia artística e social. Mediante este processo pretende-se confrontar e ensaiar soluções hipotéticas que podem reverter no próprio espaço urbano, recorrendo a visões múltiplas que em conjunto configuram um processo aberto de trabalho.

Este espaço de discussão e experimentação teve sua origem no marco de "iD Bairro SP\#01", 2010, uma colaboração entre o Museu Aberto BR e IDENSITAT. ${ }^{1}$

\footnotetext{
${ }^{1}$ BR Museu Aberto é um trabalho de arte e pesquisa em processo, no campo das artes visuais e cultura, liderado por Lilian Amaral, na cidade de São Paulo, Brasil. IDENSITAT é um projeto de arte colaborativo processual liderado por Ramon Parramon na Catalunha, Espanha. Museu Aberto BR configura-se na condição de uma plataforma de projetos entre os quais, destaca iD Bairro SP\#01 ocorrido em duas etapas, a primeira entre 13 e 17 de Outubro de 2010, em colaboração com o Centro Cultural de Espanha e da Bienal de São Paulo, com a realização de Seminário Internacional, imersão, deriva urbana e deambulações que desencadearam o desenvolvimento do projetos. Participaram Rita Alves,
} 
Museu Aberto BR e IDENSITAT são projetos de arte que investigam sobre maneiras de incidir no âmbito do espaço público através de propostas criativas em relação ao lugar e ao território com base na dimensão física e a articulação social. Constitui uma plataforma de produção e pesquisa em rede, no campo da arte, onde se experimentam novas formas de implicação e interação no espaço social. Envolve numerosos a(u)tores, de maneira individual ou coletiva, para gerar situações ou estruturas que ativem projetos que, explicitamente, dialoguem com o entorno e a complexidade social de uma determinada temática ou conjuntura. Propõe colocar em tensionamento o ultralocal e a hiperglobalização mediante a relação entre práticas artísticas, a cidade e o espaço social.

Ultralocal na medida em que explora as distintas facetas do local, a partir do conhecimento produzido pela proximidade e longo prazo, para as fronteiras que se constituem para proteger elementos como identidade, pertencimento a um determinado grupo, ou sua especificidade. A globalização envolve cada vez mais qualquer atividade realizada na cotidianidade local. Implicar práticas estéticas nesse tipo de dinâmica social e em um determinado território é um dos aspectos conceituais que definem as práticas com as quais o Aberto Museu BR tem trabalhado há duas décadas.

Em 2005 Aberto Museu BR inicia o desenvolvimento de novos projetos com o propósito de atuar em diferentes contextos com temáticas que emergiram da pesquisa e da relação com o lugar - pessoas, cidade e patrimônio local, como a "Casa de Memória: núcleo de memória audiovisual da paisagem humana de Paranapiacaba, 2006 | 2008", "Arqueologia da Memória: uma história micro na megacidade, 2004, 2007/2008, São Paulo, Curitiba", entre outros. Projetos de longa duração que propõem

Lilian Amaral, Viviana Bravo, André Costa, Rogério da Costa, Renato Cymbalista, Democracia (coletivo espanhol), Domènec, EIA - Experiência Imersiva Ambiental, Coletivo Imargem, Jamac, Fadhila Mammar e Ramon Parrmon. A segunda etapa desenvolveu-se de janeiro a setembro de 2011, $\mathrm{n}$ qual os projetos esboçados em 2010 desdobraram-se em residências artísticas imersivas e deram origem a processos que configuraram os desdobramentos resultantes no iD bairro SP \# 02 Observatório Bom Retiro, com ênfase nas questões multiculturais, preservação do patrimônio intangível e relações entre criatividade social, ação coletiva e práticas artísticas no território. O contato com IDENSITAT http://www.idensitat.net - se deu no contexto de pesquisa de Doutoramento e de Bolsa de Intercâmbio Internacional realizada junto à Escola de Comunicação e Artes da USP, por meio do Prêmio Santander Cultural, em 2008, que proporcionou um ano de pesquisas na Espanha, tendo como instituição acadêmica a Universidade Complutense de Madrid e o Programa de Pós-Graduação Aplicaciones del Arte en la integración social, coordenado pela Profa. Dra. Marián Cao. 
o protagonismo dos agentes locais como narradores e construtores da memória a partir de processos de cartografia artística e cultural

Dessa forma processual emerge o contexto para realização de iD Bairro SP, um projeto desenvolvido em conjunto a partir do encontro e da confluência entre projetos realizados no Brasil e na Espanha - Museu e Aberto BR e IDENSITAT - para a ativação de processos criativos formulados a partir da relação entre atividades educativas e a intervenção em contextos delimitados - bairros da cidade de São Paulo [BR] e de cidades da Catalunha [ES], áreas ou zonas específicas, pequenos povoados, etc - sempre que integrem uma retícula urbana mais ou menos densamente habitada.

Museu Aberto BR e IDENSITAT inspiraram as práticas e modos de fazer que tornaram o projetos seguintes redes continuadas de interações e intercâmbios artísticos, culturais e investigativos entre os dois países.

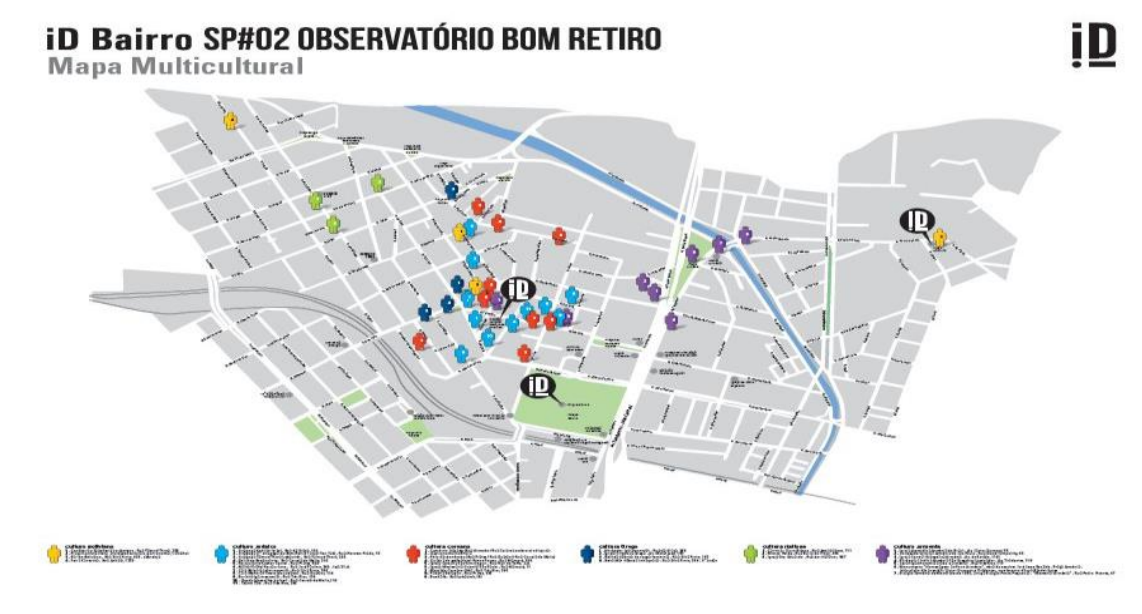

Figura 1 - iD Bairro SP - mapeamento realizado pelo projeto internacional e intercultural envolvendo os habitantes de diferentes origens culturais no bairro do Bom Retiro/região central da cidade de São Paulo, 2010/2011.

\section{R.U.A.: Realidade Urbana Aumentada. Cartografias artísticas, culturais, sociais}

R.U.A. é um projeto que atua como um observatório do território e como um laboratório para o desenvolvimento de processos criativos que se conectam a determinados atividades sociais locais, isto é, com microcontextos concretos que fazem parte de distintas concentrações urbanas contemporâneas. O projeto visa estimular a criação coletiva e o intercâmbio cultural como uma possibilidade de 
desenvolvimento e transformação do território, através de processos criativos impulsionados pela relação entre ações educativas, práticas artísticas e o espaço social local. Faz parte de seu processo analisar para entender a dinâmica do espaço, visualizar para interpretar as diversas articulações que operam nos lugares, projetar para traçar novas dinâmicas produtivas, colaborar para potencializar e multiplicar as capacidades criativas a partir de uma ação em rede, configurando "arquiteturas de relação".

O projeto estruturou-se em duas fases em relação ao espaço: uma de natureza pedagógica, articulada a partir de oficinas de projetos com processos de imersão no contexto urbano e social, discussão e tutoria, e outra, de caráter experimental, baseada na produção, entendida como desenvolvimento do trabalho proposto na primeira fase, incorporando elementos de comunicação e de visualização.

Buscou integrar os processos artísticos em outros processos sociais, visando à transdisciplinaridade, participação social, as fissuras para gerar oportunidades criadas por meio de metodologias coletivas e novas referências para o território no qual desenvolveu sua atuação. Anteriormente, todos esses elementos foram trabalhados ou testados de diferentes maneiras no contexto de processos desenvolvidos pelo projeto Museu Aberto a partir de projetos que tinham participado através de convocatória aberta ou convite. Com R.U.A. buscou-se a produção de projetos a partir de um processo pedagógico, da pesquisa científica e projeto de extensão por meio da realização de uma oficina temática ligada a um território, como "RUA: Realidade Urbana Aumentada. Cartografias Inventadas" ocorrida no contexto do bairro da Barra Funda em São Paulo, onde está sediado o Instituto de Artes da UNESP. O Instituto transferiu sua sede do bairro do Ipiranga, distrito histórico localizado na região sudeste em 2010, para um novo edifício projetado na região central da cidade, onde as linhas do espaço e do tempo se cruzam: trens, metrô, estações de ônibus, viadutos - a cidade cortada, fraturada por uma acelerada e irreversível mutação urbana.

O passado e a memória convertem-se em camadas subterrâneas no contexto da Barra Funda, onde resíduos e territórios se mesclaram: negros e italianos, o samba e o futebol, o trabalho escravo, indígena e a agricultura, o fluxo da modernidade, das indústrias que caracterizaram a fisionomia da cidade, da transição do século XIX para 
o século XX em direção ao futuro. Marcada pela presença de viadutos, pontes, malha ferroviária, a velocidade do metrô e as conexões das redes digitais, esta paisagem em mutação cede lugar a novos cenários ultramodernos que emergem rapidamente e se voltam aos interesses do mercado imobiliário, onde torres de comunicação, edifícios monumentais de quarenta, cinquenta andares eclipsam as chaminés que resistiam até pouco tempo, como num esforço de rememorar os distintos lugares da memória coletiva.

Poucas questões afetam de forma tão perturbadora nossos castelos do saber como o que nos coloca hoje a cidade. A transformação está afetando o lugar mesmo de onde formulamos a seguinte questão: de onde olhar e ler a cidade para compreendermos suas dinâmicas e incidir sobre as lógicas perversas da funcionalidade e da exclusão?

Trata-se, pois, de ler a cidade não como um objeto ou uma forma, mas como escritura que se desfaz e refaz cotidianamente em muitos planos e com muitos diferentes materiais, assim como dela participam tanto gestores como atores, tanto governantes como cidadãos. A cidade, ainda hoje, se escreve no mais antigo e denso modo de escritura: o do palimpsesto. Se no passado o palimpsesto resultava da escrita em pedaços de cera que eram apagados, ao reescrever no mesmo suporte, mesclavam-se muitos fragmentos, pedaços de palavras ou frases das escrituras anteriores, emergindo palavras mescladas às da nova escritura. Agora, o palimpsesto é a escritura que se faz não apenas com o que se escreve no presente, mas também com todos os resíduos que resistem e operam desde a própria memória do suporte e da sua materialidade. Assim está escrita a cidade. Martín Barbero propõe a leitura urbana

a partir da multiplicidade de suas camadas tectônicas e da polifonia de suas linguagens, no seu fecundo caos e seu desconcertante labirinto, transformando o palimpsesto em aposta metodológica: um lugar de vislumbre e fuga dos sentidos, enquanto dispositivo do sentir, do olhar, do cheirar, do tocar e do ouvir. Se como escritura o palimpsesto é o passado voltando a emergir nas entrelinhas com que se escreve o presente, agora o assumimos como foco e fuga, ou seja, como modo dever, em uma percepção que, como a entendeu Merleau-Ponty (1945), é percepção constituinte do conhecer (BARBERO, 2008, p. 2. Tradução livre). 
O passado guarda em si diálogos que o presente deseja resgatar. Andréas Huyssen comenta que desde a década de 1970 observa-se, na Europa e Estados Unidos, uma curiosa proliferação de práticas da memória:

\begin{abstract}
a restauração historicizante de velhos centros urbanos, cidades-museus e paisagens inteiras, (...) a onda da nova arquitetura de museus (que não mostra sinais de esgotamento), o boom das modas retro e dos utensílios reprô, a comercialização em massa da nostalgia, a obsessiva automusealização através da câmera de vídeo, (...) a difusão das práticas memorialísticas nas artes visuais, geralmente usando a fotografia como suporte, e o aumento de documentários na televisão, incluindo, nos Estados Unidos (e agora no mundo inteiro), um canal voltado para a História: o History Channel' (HUYSSEN, 2000, p. 18)
\end{abstract}

$\mathrm{Na}$ concepção de Huyssen, a olhada para o passado viria para compensar a perda da estabilidade que o indivíduo tem com seu presente, sendo, portanto, um modo de neutralizar os efeitos de uma inserção excessivamente fluida do indivíduo na sociedade. Dessa maneira, vemos que as práticas da memória expressam, para Huyssen, a necessidade de uma ancoragem espacial e temporal em um mundo moldado por redes cada vez mais densas de espaço e tempos comprimidos.

No âmbito da "cultura da memória", qual pode ser a abordagem sobre o patrimônio cultural de uma cidade na atualidade? As cidades, como paisagens contemporâneas são ambientes saturados de inscrições, campos que acumulam antigas edificações, monumentos, museus, vestígios arqueológicos, riscos de memórias como sínteses de experiências históricas justapostas.

Cabe ainda questionar a forma elaboramos o que vemos no âmbito do patrimônio cultural urbano? Como interage nossa sensibilidade na cidade onde vivemos? O que retemos na memória das experiências ocorridas na cidade? Qual a contribuição que a arte pode dar a essas inquietações?

Para Félix Guattari (2006, p. 115) é nas trincheiras da arte que se encontram os núcleos de resistência dos mais consequentes às pressões da subjetividade capitalista. Não se trata de fazer dos artistas os novos heróis da revolução, as novas alavancas da história, mas a arte evoca toda a criatividade subjetiva que atravessa os povos e as gerações oprimidas, os guetos, as minorias.

Como, então, pensar a arte em relação ao patrimônio cultural das cidades onde vivemos? 
Entendemos que o patrimônio cultural, pelo seu teor simbólico e sua significação, funciona como suporte para evocar e convocar a memória, como fenômeno social que articula passado e presente [re]criando e [re]definindo imagens da cidade.

O trabalho de arte, dessa forma, configura-se como dispositivo privilegiado, uma espécie de tecnologia de processamento sensorial, com a potencialidade para, no encontro com o corpo/mente do espectador, fazê-lo sair da posição de observador neutro da cidade, testemunha imparcial, indiferente, e colocá-lo também em ação, a mover-se percebendo a cidade enquanto nela se percebe.

Então, talvez a arte possa vir a ser o fio de Ariadne no labirinto da cidade, ajudando-nos a olhar e sentir o que venha a ser patrimônio cultural para cada um de nós, provocando nossos sentidos a gerar sentidos outros, mesmo que ininteligível, que nos amarre à memória da cidade.

Com esse olhar da arte é que os projetos Museu Aberto BR, IDENSITAT e R.U.A.: Cartografias inventadas estabeleceram conversas com o público, realizando diferentes ações artísticas que buscaram estabelecer pequenos lapsos, interrupções no cotidiano das cidades, provocações em que a arte e artistas escavaram outros modos e fluxos de informações sobre o patrimônio cultural na vida ativa dos cidadãos, criando atravessamentos e encontros poéticos.

\section{O museu e a rua: a museificação dos centros urbanos contemporâneos. ${ }^{2}$}

$\mathrm{Na}$ atualidade é comum encontramos exemplos que mesclam por um lado os valores associados à arte e à cultura em geral e, por outro, grandes dinâmicas de mutação urbana de um amplo espectro. As políticas de reconversão e reforma urbana que estão transformando tanto a fisionomia humana quanto morfológica das cidades consistem em favorecer os processos de gentrificação e tematização dos centros históricos, assim como a renovação de bairros inteiros previamente abandonados a processos de deterioração para sua posterior requalificação como zonas residenciais

\footnotetext{
${ }^{2}$ Sobre este tema, consideramos as ideias apresentadas em palestra do Antropólogo e curador Manuel Delgado e a urbanista Raquel Rolnik, que integraram o Ciclo de Debates em Arte Pública e Museus Urbanos Contemporâneos, realizados no Centro Cultural da Espanha em São Paulo, 2009.
} 
de categoria superior ou para sua adaptação às novas indústrias tecnológicas que demandam lógicas globalizadoras.

Esses processos de transformação urbana são realizados, quase sem exceção, por todo tipo de atuações que invocam aos princípios abstratos da Arte, Cultura, Beleza, Sabedoria, etc. - valores nos quais as políticas de promoção urbana e a competição entre cidades encontram um valor a ser dotado de singularidade funcional e prestigio do que na prática são estratégias especuladoras e sensacionalistas, além de se constituírem em fonte de legitimação simbólica das instituições políticas diante da própria cidadania.

Nesse contexto, o estabelecimento de grandes conteúdos artístico-culturais em lugares-chave aparece como uma espécie de adorno que acompanha uma reativação do espaço urbano efetuada, partindo sempre de critérios de puro mercado e que acarreta, por sua vez, operações de exclusão social daquela população que não será considerada "à altura" do novo território reativado. Tais iniciativas - quase sempre entregues à confiança de arquitetos-estrela - recebem a responsabilidade de executar tarefas que não são novas: de um lado, adornar a cidade, enfatizando os valores de harmonia, sugerindo a vida urbana ideal como experiência estética e, do outro, desemaranhar a cidade, contribuir com a sua esquematização, oferecer lugares claros e esclarecedores nos quais se possa identificar com simplicidade o que deve ser visto e como fazê-lo, desativando ou diminuindo a crônica tendência do urbano à opacidade.

R.U.A.: realidade urbana aumentada, ao engajar o público na condição de cartógrafo e performer do lugar, opera na contramão ao sentido de gentrificação dos espaços urbanos. Propõe micro ações de reexistência poética como antídotos à espetacularização e especulação imobiliárias, inscrevendo formas inovadoras de experimentação e reinvenção de relações entre pessoas, cidades e memórias, por meio da criatividade social, ação coletiva e práticas artísticas no presente. 


\section{R.U.A: Realidade Urbana Aumentada. Cartografias Inventadas}

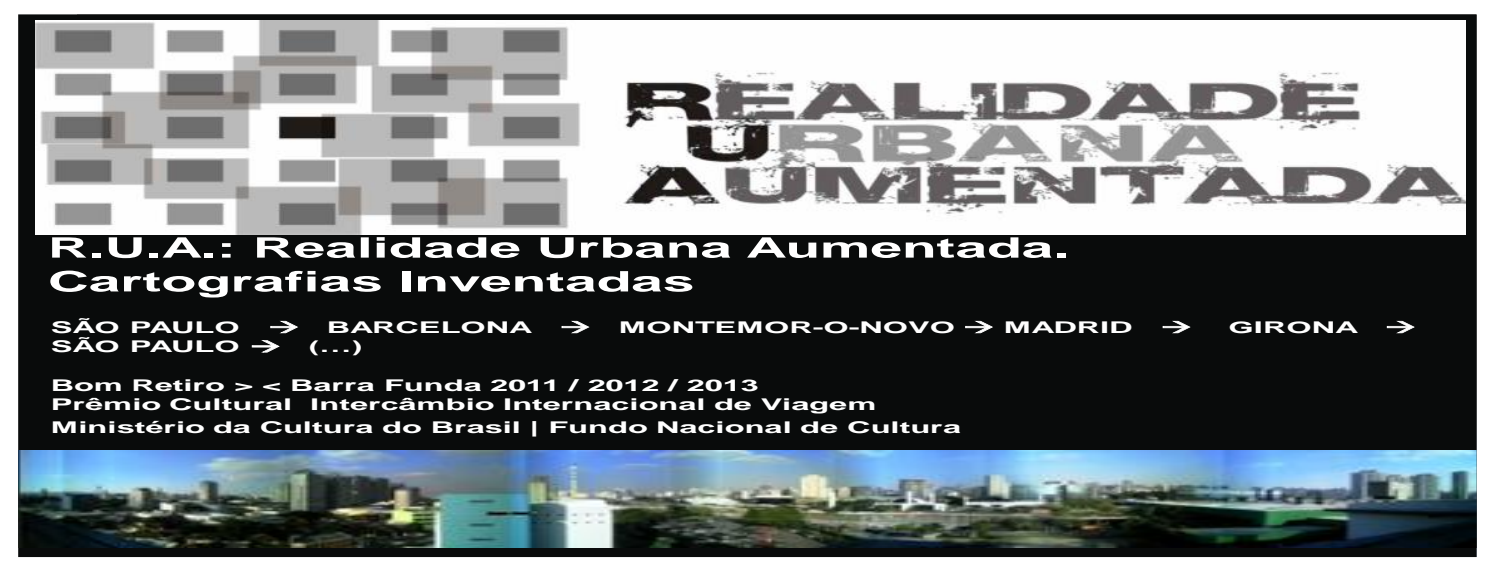

Figura 2 - R.U.A. Cartografias Inventadas - plataforma colaborativa para a implementação de ações, dispositivos e intervenções urbanas em espaços públicos.

R.U.A. configura-se eminentemente como investigação processual e opera com as concepções de Cartografias Culturais - da sensibilidade e a tecnicidade, que se complementam com as noções de Cartografia Social. Estabelecem uma aproximação entre museu e cidade, nas quais as cartografias sociais e culturais podem converter-se em lugares onde se encontrem e dialoguem as múltiplas narrativas e temporalidades do mundo. R.U.A. pretende investigar as memórias e conectar cidades em rede desenvolvendo experiências em contextos latinoamericanos. Inscreveu-se como campo de ação de Pós-Doutoramento realizado no Instituto de Artes da UNESP - Universidade Estadual Paulista, São Paulo, Brasil, e Universidade de Barcelona, Catalunha, Espanha. Operou articulações entre arte contemporânea, memória e identidade, propondo experimentar a cidade como campo ampliado para as artes audiovisuais, entendendo a paisagem cultural (natural, construída e humana) como uma rede de trocas simbólicas e de conhecimentos, dando lugar a transformações e cruzamento estéticos e éticos no âmbito da micropolítica contemporânea.

A proposição "RUA: Realidade Urbana Aumentada. Cartografias Inventadas" configurou-se enquanto plataforma colaborativa para a implementação de ações, dispositivos e intervenções urbanas em espaços públicos na região central da cidade de São Paulo e em Barcelona, em uma primeira fase, e em uma segunda instância implementou uma rede de intercâmbio de pesquisa em arte e cartografia social, com outras cidades europeias e latino-americanos, como Girona e Valência, na Espanha, 
Montemor-o-Novo em Portugal, Bogotá na Colômbia, onde questões sobre o patrimônio e a memória são os eixos de mobilização de um amplo debate cultural.

Incide na esfera coletiva, da pesquisa-ação e do processo de intervenção colaborativa em processo, articulado à Linha de Pesquisa Arte e Media City, coordenada por esta pesquisadora, junto ao Programa de Pós-Graduação em Artes Visuais do Instituto de Artes da UNESP, São Paulo, Brasil. Integra o GIIP - Grupo Internacional e Interinstitucional de Pesquisa em Convergência entre Arte, Ciência e Tecnologia, liderado pela pesquisadora Rosângella Leote e é associado a uma rede de pesquisadores artistas que atuam em diferentes países. Envolve pesquisadores acadêmicos e culturais, não se restringindo aos integrantes do GIIP, compondo, desta forma, uma arquitetura de relações interterritoriais, envolvendo corpo discente, docente e comunidade cultural internacional. Integram, nessa colaboração Inês Moura (Portugal), Brito Bruno, Fernanda Duarte, Gustavo Bartolini, Lucimar Bello, Rogério Rauber, Carlos Dias, Augusto Citrângulo, Prof. José Laranjeira e Prof. Dr. Prof José Xaides, ambos da FAAC de Bauru/UNESP, Daniel Paz pela PUC/SP no Brasil, e Prof Dr. Josep Cerdá da Universidade de Barcelona, Joan Vallés, Universidade de Girona, Maribel Domènec, Emílio Martinez e Bia Santos, da Universidade Politécnica de Valencia, Espanha e Tiago Fróes em Montmor-o-Novo, Portugal. ${ }^{3}$

R.U.A., na condição de Museu Efêmero foi organizado em dois módulos distintos e consecutivos, no âmbito de atividades de Extensão Universitária, desenvolvido ao longo de 2012 e 2013: São Paulo - Grupo Internacional e Interinstitucional de Pesquisa em Convergência entre Arte, Ciência e Tecnologia, Junho, 2012, "RUA:. Realidade Urbana Aumentada. Cartografias Inventadas", campo urbano expandido, baseado no Instituto de Artes/UNESP, no bairro da Barra Funda, São Paulo, de maio a setembro de 2012 e Observatório R.U.A., Centro Cultural Sant Agustí em conjunto com a Universidade Barcelona, abrangendo os bairros de San Pere, Santa Caterina e La Ribera, no centro histórico da cidade, em outubro de 2012, seguido de Valencia, junto à Universidade Politécnica de Valência abrangendo o bairro de Cabanyal, Girona, em conjunto à Univdersidade de Girona, incidindo no Centro Histórico da cidade, bairro de San Feliu e, por fim, em novembro, a cidade de

\footnotetext{
${ }^{3}$ Em Montmor-o-Novo ver Oficinas do Convento http://www.oficinasdoconvento.com. Em Valência ver http://cabanyalarchivovivo.es.
} 
Montemor-o-Novo, junto à Oficinas do Convento | Convento São Francisco, atuando a partir de todo o território urbano/rural. Em 2013 foi realizado o II Encontro Internacional "Patrimônio em Transição: conceitos e práticas de mediação contemporânea", com a participação de Marcello Falcón e Apolline Torregrosa, da Universidade de Sorbonne, França, pesquisadores vinculados ao Observatório de Educação Patrimonial - OEPE, estabelecendo as bases atuais para a realização do II Congresso Internacional de Educação Patrimonial, a ocorrer em Madrid, Paris e São Paulo, sob direção de Olaia Fontal, professora titular da Universidade de Valladolid, Espanha, a realizar-se entre 28 e 31 de Outubro de 2014, quando será firmada a Rede Internacional de Educação Patrimonial. ${ }^{4}$

Investigam-se os modos de fazer artísticos e culturais que implicam em novas perspectivas para gestão do patrimônio colaborativo no âmbito da Educação Patrimonial, com base nos dispositivos e estratégias que emergem do campo da arte, tecnologia e "cultura virtual".

Atravessamos uma revolução tecnológica cuja peculiaridade não reside tanto em introduzir em nossas sociedades uma quantidade inusitada de novas máquinas, mas definir uma nova relação entre os processos simbólicos - que constituem o cultural - e as formas de produção e distribuição de bens e serviços: segundo nos propõe Castells (2003) uma nova maneira de produzir, associada a um novo modo de comunicar, converte a informação e o conhecimento em força produtiva direta.

A partir dos mapeamentos realizados nos territórios, artistas e comunidade participantes das oficinas e Seminário Internacional propostos no primeiro semestre, desenvolvem cartografias digitais em rede, em conexão com os coordenadores (artistas pesquisadores), atores locais e extralocais.

O desenvolvimento de cartografias culturais e sociais é realizado por grupos de cooperação, assim como projetos de intervenção poética que se articulam com a finalidade de dar visibilidade a características específicas do patrimônio cultural local.

Nesse contexto, o objetivo centra-se, junto a pesquisadores e representantes de organizações internacionais em contexto Ibérico, Latino-americano e no Brasil, na

\footnotetext{
${ }^{4}$ http://www.oepe.es/congreso
} 
importância e a transcendência da inovação científica no campo da preservação da memória e do patrimônio tangível e intangível, das possibilidades de trabalhos colaborativos na dimensão artística nos territórios [inter]culturais em risco de crise, bem como na sustentabilidade e evolução dos processos de participação popular no planejamento e na gestão desses territórios.

Inscreve-se como um lapso, uma desaceleração na percepção e experiência urbana, com a criação de perspectivas de reinterpretação, apropriação crítica e de pertencimento. Estimula abordagens interpretativas sobre a configuração do patrimônio cultural urbano por meio das Artes, Educação Patrimonial, Tecnologia da Informação e Comunicação.

Cria um campo de prática transdisciplinar, como o próprio território sobre o qual incide - Património Cultural, Memória-Cidade, que envolve um trabalho no qual os artistas, educadores, gestores públicos e as comunidades locais sejam os protagonistas no mapeamento social e em narrativos audiovisuais. Essas experiências são parte de uma plataforma multiusuários que integra pesquisadores e coletivos vinculados a pesquisas no campo em que se estabelecem convergências entre arte, ciência e tecnologia.

R.U.A. configura-se, dessa forma, como Cartografias Multisensoriais desenvolvidas pela rede de trocas estabelecidas pelo GIIP, incorporando as práticas e reflexões desenvolvidas em contextos e territórios multiculturais ibero-americanos. Paisagens sonoras, ações performáticas no território, intervenções e colaborações artísticas, criações audiovisuais com projeções em espaços públicos são desenvolvidas juntamente a um programa paralelo de mediação cultural, envolvendo estudantes, pesquisadores, residentes e estagiários baseados no entorno da UNESP, ampliando, assim, sua inserção, diálogos e conexões ultralocais. Todas as etapas do projeto são sistematicamente publicadas na rede, abertas à colaboração e em processo de desenvolvimento constante. 


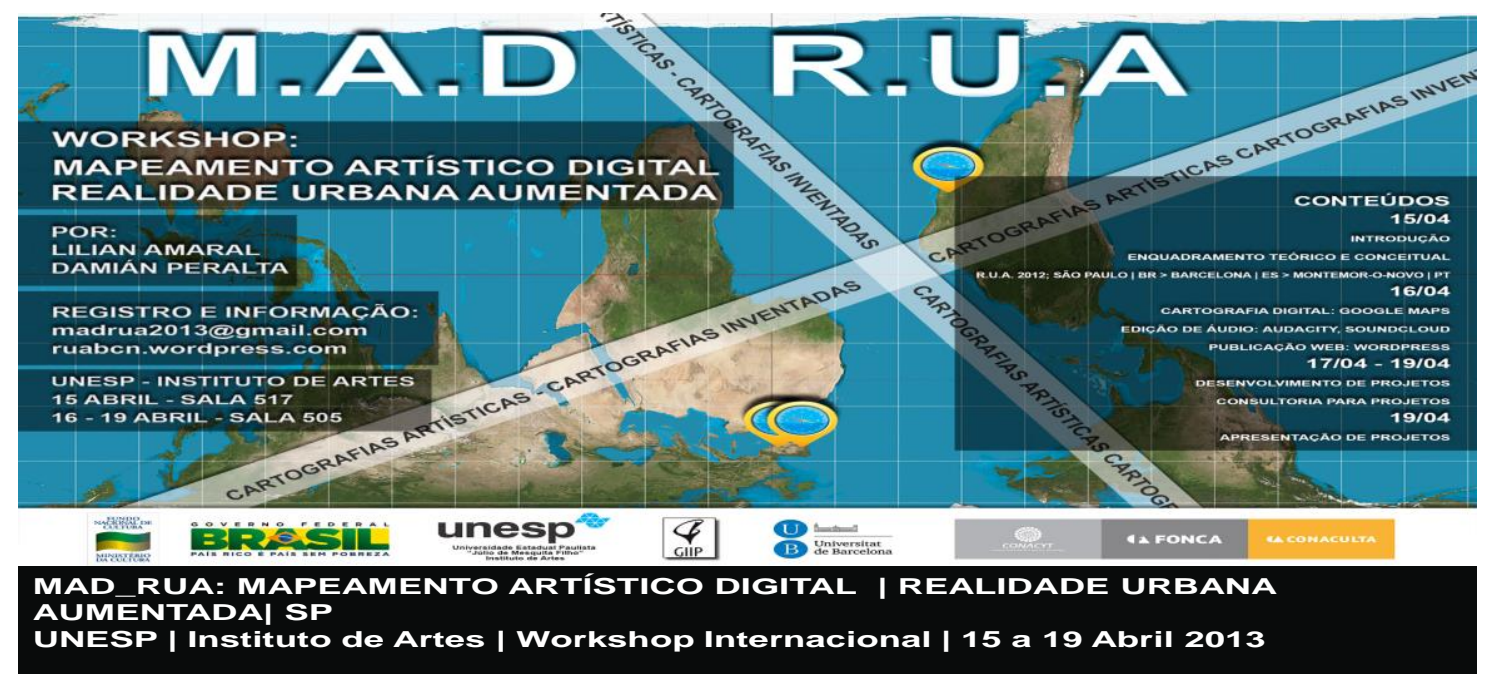

Figura 3 - Mapeamento Artístico Digital opera com Cartografias Digitais [Sonoras, Visuais, Sociais, Afetivas], estabelecendo diálogos entre as cidades de São Paulo e Barcelona.

Nesta perspectiva de colaboração e criação em rede, ou seja, numa perspectiva da cultura virtual, Hopenhayn nos informa que

\begin{abstract}
As trocas virtuais definem novos traços culturais à medida que tais intercâmbios se intensificam e expandem para uma gama crescente de esferas da vida das pessoas. Sobre isso, fala-se cada vez mais de "culturas virtuais" para se referir à mudanças nas práticas comunicativas por efeito das mídias interativas à distância, que modificam a sensibilidade dos sujeitos, suas formas de compreensão do mundo, a relação com os outros e as categorias para apreender o entorno. As culturas virtuais são mediações entre cultura e tecnologia, constituem sistemas de troca simbólica mediante os quais se configuram sentidos coletivos e formas de representação do real (HOPENHAYN, 2005, p. 73).
\end{abstract}

A digitalização torna possível a um só tempo a visibilização local e global de nosso patrimônio, incluindo-se aqui de uma maneira especial uma "posta em comum" dos diversos patrimônios nacionais e locais latino-americanos. De um lado, trata-se de democratizar, isto é, de aproximar o acervo patrimonial desses países aos seus próprios cidadãos para seu conhecimento e apreciação, para o cuidado da memória histórica "real" - não oficial nem homogênea, mas plural - e sua apropriação por parte das diversas gerações e populações mais distantes da metrópole. E de outro lado, trata-se de uma nova maneira de como as nossas culturas estão no mundo, mostrando a riqueza da história e da criatividade do presente, desmontando clichês e estereótipos exóticos, atraindo o turismo. E isso nas múltiplas formas que hoje permite o hipertexto: em imagens estáticas e em movimento, sonoridades e a música, em 
códigos e textos. Mediante banco de dados, imagens, histórias orais, músicas, canções, imagens, fundos temáticos e exposições virtuais.

As redes digitais não são unicamente um local de preservação e difusão do patrimônio cultural e artístico, mas um espaço de experimentação e criação estética. A experimentação hipertextual possibilita novas formas de fazer arte através da arquitetura de relações e linguagens que até agora não tinham sido atualizáveis. De outro lado a conectividade interativa redefine a excepcionalidade das "obras" e da singularidade do artista deslocando os eixos da estética para as interações e os acontecimentos, para um tipo de "obra" permanentemente aberta à colaboração dos navegantes criativos.

Metáfora para novas formas de social, a criação na web possibilita performatividades estéticas que a virtualidade permite, não só para o campo da arte, mas também para a recriação da participação social e política, atravessada pela ativação de várias sensibilidades e sociabilidades até agora consideradas como incapazes de atuar, criar e interagir com a contemporaneidade técnica.

\section{Referências}

AMARAL, L. ID Bairro SP\#02 OBSERVATÓRIO BOM RETIRO. Disponível em: <http://idensitat.net /idbairrosp>. Acesso em: 20 de julho. 2012.

AMARAL, L.; CERDÀ, J. Definição: R.U.A. BCN, 2012. Acesso em 13 de Abril de 2014: <http://ruabcn. wordpress.com/definição>

BARBERO, J. M. In-Signis. Barcelona: Gedisa, 2008.

CASTELLS, M. A era da informação. v.1. Madrid: Alianza, 2003.

GIIP - Grupo Internacional e Interinstitucional de Pesquisa em Convergências entre Arte, Ciência e Tecnologia / UNESP. Disponível em: <http://www. giip.ia.unesp.br>. Acesso em: ago./2014.

GUATTARI, F. Caosmose: um novo paradigma estético. 4ae ed. São Paulo: Ed. 34, 2006.

HOPENHAYN, M. América Latina desigual e sem foco? Buenos Aires: Standard, 2005.

HUYSSEN, A. Seduzidos pela memória: arquitetura, monumentos, mídia. 2. ed. Rio de Janeiro: Aeroplano, 2000.

PARRAMON. R. (Org.). Arte, experiência e territórios em processo. Espaço Público/Espaço Social. Calaf / Manresa: IDENSITAT Asociación de Arte Contemporáneo, 2007.

R.U.A. BCN Realidade Urbana Aumentada. Disponível em: <http://vimeo.com/63506037>. Acesso em: ago./2014.

RUAS: Cartografias Inventadas. Disponível em: <http://youtu.be/ly-qGEgQNtE>. Acesso em: ago./2014.

ZONAS DE COMPENSAÇÃO. Disponível em: <http://zonasdecompensacao.wordpress.com>. Acesso em: ago./2014. 


\section{Lilian do Amaral Nunes}

Artista Visual, Pesquisadora e Curadora Independente. Pós-Doutoranda e docente junto ao Programa de Pós-Graduação em Arte e Cultura Visual da Faculdade de Artes Visuais da UFG. Pós-Doutorado em Arte, Ciência e Tecnologia pelo IA/UNESP. Doutora em Artes pela Escola de Comunicações e Artes da Universidade de São Paulo. Mestre em Artes pela Escola de Comunicações e Artes da USP. Graduada em Licenciatura em Artes pela Fundação Armando Álvares Penteado FAAP. Pesquisadora Capes/CNPq - GIIP - Grupo Internacional e Interinstitucional de Pesquisa em Convergência entre Arte, Ciência e Tecnologia - IA/UNESP. Ministra conferências, cursos e workshops relacionados à revitalização urbana, memória, imaginário social e práticas artísticas colaborativas. Extensa produção de Vídeos e Documentários. Pesquisadora no Campo da Museologia Urbana Contemporânea com ênfase em Curadoria e processos colaborativos, Arte Pública, Preservação do Patrimônio Material e Imaterial, Educação Patrimonial e Cidades Criativas.

E-mail: lilianamaral@uol.com.br

Currículo: http://lattes.cnpq.br/9200107012768155 